\title{
DA ETIMOLOGIA E DEFINIÇÃO DO DOMÍNIO
}

\author{
Euclides de Queiroz Mesquita \\ Professor da Faculdade de Direito da \\ Universidade do Paraná
}

\begin{abstract}
O Digesto, em seu Tit. XVI - De Verborum Significatione - trata dos têrmos técnicos em direito romano. Como aviso das dificuldades que se antolham ao problema, Javoleno, no Tit. seguinte, no Fr. 202, nos avisa do perigo das definições jurídicas, quando diz:- "Omnis definitio in jure civili periculosa est, parum est enim ut non subverti possit" - por ser difícil achar algumas que não possam vir abaixo.

Em comentário a êsse fagmento 202, em seus Prolegômenos, o grande André Dupin (André Marie Jean Jaques) dito Dauphiné (1783-1865) explica: "dificílimo e muitas vêzes impossível é formular uma regra jurídica (referindo-se também às definições) que compreenda todos e sòmente os casos a que se deva aplicar; uma simples diferença de circunstâncias altera quasi sempre todo o direito. Devemos, por isso, tomar as regras jurídicas como abrangendo a maior parte dos casos, não todos".
\end{abstract}

Parece, todavia que se não deve aí compreender tôdas as regras e definições de direito, porque algumas há rigorosamente precisas.

Sem considerarmos os brocardos, atentemos apenas para os requisitos que a lógica exige para uma definição exata, por exemplo, a de domínio.

P. Cogliolo, no vocabulário com que completou a sua "Storia del diritto privato romano" (1896) atribui a "dominium" 
e a "dominus" idêntica raiz que a "domus" - casa - explicando que se origina de "da" — ou seja, ligar, vincular. Sabe-se que as fontes dêsse vocabulário são os trabalhos lexicológicos de Alois Vaniçek, H. L. de Roby e Ruggiero.

Encontra-se no Dicionário de M. Bréal e A. Bailly êsse mesmo parentesco colateral entre "domus" e "dominus" e filiados, não à raiz "da", mas à raiz "dem" - construir, edificar, raiz que se encontra no Diccionário grego de A. Chassang (1905), e para "domus" apenas (Racines et Radicaux) e não para "dominus" e "dominium".

Parece-nos, e é mais provável, pelas considerações que adiante alinharemos, que "dominus" não provém da mesma raiz que "dominus", seja ela "da", como sugere Cogliolo, seja "dem" como indicam Bréal e Bailly.

"Domus" ao que parece, segundo o Magnum Lexicon, (Parisiis, 1849), tem sua origem em "dem" - construir, e não em "da" - vincular; de outro lado, "dominus" - dono não se origina nem de "dem", nem de "da" e sim, ao que parece, de "do", raiz afirmativa de dar, distribuir - o que se confirma com os exemplos de: dote, dação, dom, etc.

O "minus" de "do-minus", da mesma maneira que o "mini" das 2. as pessoas do plural dos verbos na voz passiva, representa o "menos" sufixo participal médio do grego.

"Dominus", parece, é o "dominis", particípio médio de "didoni" - dar — no aoristo particípio indefinido. Assemelha-se ao fato de, numa como passividade indireta, a pessoa a quem a coisa foi dada. É um verbo cuja conjugação encontra-se em tôdas as gramáticas gregas. Através o sufixo nominal - io - fez-se de "domino" — dono - "dominium", como de senhor se fêz senhorio.

Não há em todo o Corpus Juris Civilis uma só definição de domínio ou propriedade. No entretanto, abalisados romanistas, como van Wetter tentam apresentá-la, baseando-se nos textos daquela soberba compilação, mau grado o receio de Javoleno. Van Wetter definiu "domínio", como um direito ilimitado sôbre a coisa e baseia sua definição no $\S 4 .^{\circ}$ das Institutas, II, 4. De Usufructu: Cum autem finitus fuerit usufructus, revertitur scilicet ad proprietatem, et ex eo tem- 
pore nudae proprietatis dominus incipit plenam in re habere potestatem.

É preciso considerar, todavia, que, quando êsse $\S$ diz que, com a extinção do usufruto, a propriedade que era até então nua, torna a ser novamente plena, indica claramente que há propriedade sem poder absoluto sôbre a coisa.

A mesma consideração é de se fazer com o direito real e exclusivo, dado como definição de domínio por Maynz.

Analisando o art. 544 do Cód. Civil Francês - La proprieté est le droit de jouir et disposer des choses de la manière la plus absolue, pourvu qu'on n'en fasse pas un usage prohibé par les lois ou par les règlements - inspirado na definição de Pothier, vê-se que o direito de gozar e dispor da coisa pode exercer-se da "maneira mais absoluta", mas acrescenta logo "contanto que não se faça dêle um uso proibido pelas leis e regulamentos, omitida aí a limitação dos ônus reais que torna menos pleno o domínio.

O Código Civil italiano de 1865, em seu art. 436, traduz o francês do Código Civil de Napoleão - verbo ad verbum: La proprietá é il diritto de godere e disporre delle cose nella maniera la piú assoluta, purché non se ne faccia un uso vietato dalla legge e dai regolamenti.

No atual Código Civil Italiano - art. 832 - Il proprietário ha diritto di godere e disporre delle cose in modo pleno ed esclusivo, entro i limiti e con l'osservanza degli obblighi stabiliti dall'ordinamento giuridico - o direito de gozar e dispor das coisas, é pleno e exclusivo, com as limitações impostas pelo direito.

É o mesmo sentido, com outras palavras, estando implícitos, na limitação, os ônus reais.

Encontramos no Código Civil Austríaco, o domínio considerado como o poder de dispor à vontade da substância da coisa e seus produtos, com exclusão de outrém. É a definição adotada por jurisconsultos alemães de época anterior à promulgação dêsse Código de 1811. Revela a sua origem na definição de usufruto dada nas Institutas:- usufructus est jus alienus rebus utendi, fruendi, salva rerum substancia.

O Código Civil Alemão, em seu artigo 903 e o Suíço, em 
seu artigo 641, não definem o domínio: aquêle diz: "Le propriétaire d'une chose, si la loi ou les droits des tiers ne s'y opposent, peut se comporter à l'égard de la chose comme il l'entend et écarter toute entreprise de la part des tiers". Code Civil Allemand - Traduit par O. de Meullenaere. MDCCCXCVII,

- êste dispõe: "Le propriétaire d'une chose a le droit d'en disposer librement, dans les limites de la loi.

"Il peut revendiquer contre quiconque la détient sans droit et repouser toute usurpation".

Assim, é claro que os dois referidos códigos limitam-se a declarar que o proprietário dispõe livremente da coisa, desde que não o faça infringindo a lei ou ofendendo direitos de terceiros.

As disposições que os dois códigos encerram em um só artigo, encontram-se no Código Civil Brasileiro mais desenvolvidos nos artigos 524 a 527, ainda com um pequeno lapso, neste último artigo, quando se refere a domínio exclusivo e ilimitado, quando devera referir-se a domínio pleno para guardar harmonia com o artigo 525.

Analisando a definição que Pothier dá ao domínio, vê-se que a mesma se cinge em declarar ser o domínio um direito que se pode exercer em conformidade aos limites traçados nas leis e regulamentos.

Afinal, nada explica, pois todos os direitos são enquadrados nesta espécie.

Vê-se, assim, que a definição vai além do definido. $\mathrm{E}$, portanto, viciosa: soli definitio conveniet.

Se manuseamos os autores modernos, nada encontramos para dirimir a questão: todos dizem, em outras palavras o que Pothier declarou há 2 séculos.

Vareilles Sommiéres, por exemplo, define domínio "o direito pelo qual uma pessoa pode, em princípio, tirar da coisa, tôdas as serventias". Já aí ha restrição, pois a expressão "em princípio" contida na definição, quer significar, em regra, normalmente, admitindo, de conseqüência, limites à ação do proprietário. 
Resulta que se volta ao ponto inicial e se fixa a matéria novamente em Pothier que teve a vantagem de não precisar defender sua definição com o ridículo a que se expôs Vareilles Sommiéres, distinguindo entre os adjetivos "inteiro" e "incompleto", chegando a afirmar que um carvalho novo é inteiro, mas incompleto... quando se sabe que não é a árvore, mas seu tamanho que está incompleto.

Os inovadores insistem em se estender em longas dissertações para fazerem aceitas suas longas logomaquias cujo conteúdo é inócuo e estéril..

Nada disto serve aos propósitos honestos dos estudiosos e as tentativas dêsses falsos juristas, pejadas de germanismos vistosos, mas indigestos, destinam-se apenas a perturbar a sinceridade dos estudos aprofundados.

Assim, muita coisa se transcreveu do direito estrangeiro para o nosso, em matéria de domínio, e muitas vêzes sem aplicação às nossas condições jurídicas, e ainda assim, de autores alienígenas que versarem mal o próprio direito nacional!

Não se pode afastar, pois, da análise da definição de propriedade certos aspectos sociais. Propriedade é noção que existe desde o comêço do mundo e coisa que constantemente está em nossas ações, pela constância de todos em possuir, em adquirir, em transferir... Não parece, pois, haver nenhuma necessidade numa boa definição de domínio, dado o sentido que todos têm da coisa, revela-se natural e compreensivo, e daí porque raros, senão raríssimos, são os textos de lei que procuram definí-lo, atendendo, assim à advertência de Javoleno.

Não obstante êste sensato aviso, arriscamo-nos a tentar uma definição de domínio, no sentido de uma operação lógica, apenas:- Domínio é o direito real que se concebe sem a existência de outro e sem cuja coexistência a de outro não é possível.

Como dissemos acima, a definição obedece aos preceitos rigorosos de uma operação lógica: é clara, sem nenhuma expressão vaga ou ambígua; é breve, sem obscuridade, todavia; é recíproca, pois o sujeito da oração principal pode passar a atributo e o atributo a sujeito. Nela está expresso o 
gênero "direito real" - e a diferença específica do direito de que se trata.

Apelo para a egrégia competência de autores, como o Cardeal Mercier, ou mesmo o Abade Barde e o Padre Gaffré, da Companhia de Jesus, que sabiam dizer o que ensinaram e ensinavam porque sabiam. E apelo ex-ofício. 